\title{
NOAA's Certification program in Marine Cartography
}

\author{
Shachak Pe'eri ${ }^{\mathrm{a},}$, John Nyberg ${ }^{\mathrm{a}}$, Neil Weston ${ }^{\mathrm{a}}$ \\ ${ }^{a}$ Office of Coast Survey, National Oceanic and Atmospheric Administration, Silver Spring, MD, USA (Shachak.peeri@NOAA.gov, \\ John.Nyberg@NOAA.gov, and Neil.D.Weston@NOAA.gov) \\ * Corresponding author: Shachak Pe'eri (Shachak.peeri@NOAA.gov)
}

Keywords: Marine Cartography, Building Capacity, Education, Nautical Charts

\begin{abstract}
:
Since its establishment in 1807, the National Oceanic and Atmospheric Administration's (NOAA) Office of Coast Survey has provided nautical charts to support safe shipping, national defence, and the delamination of maritime boundaries. The mission of the office is to provide navigation products and services that ensure safe and efficient maritime commerce on America's oceans and coastal waters, and in the Great Lakes. The Office of Coast Survey employs cartographers, hydrographers, physical scientists, managers and administrative staff in order to fulfil its mission. Until recently, training in nautical cartography at the office of Coast Survey was conducted at the branch level and differed based on level of employee seniority (i.e., Entry, Intermediate and Advanced) and the processing branch of the employee. Over the past two years, NOAA has established a Coast Survey CAT B program that is intended to train and educate to up to 13 cartographers per year in nautical cartography, through a combination of lectures, hands-on chart production experience, details to various branches within the Coast Survey, and field trips to working hydrographic survey vessels through six training modules spread over a one-year period, spread over six courses that include:
\end{abstract}

- Refresher course that provides a review of the basic math, computer and communication technology, marine geography, hydrography, and geodetic topics. The goal of this course is to ensure that students have a sufficient academic background to succeed in the subsequent CAT-B program courses and other activities.

- Introduction to Cartography course that reviews elements of cartography, specifically scale, design, and data manipulation techniques. Students will gain an appreciation for maps and map-making, including manual techniques. This introductory course will include hands-on use of computer graphics tools.

- Map Design course that reviews the various styles and techniques associated with cartographic design. The course will require the student to: 1) analyse chart design parameters, 2) compile thematic cartographic projects, and 3) experiment with map design.

- GIS and Spatial Analysis course that provides students with a comprehensive understanding of spatial analysis methods and they will learn practical skills in using GIS and spatial analysis. The class covers the methods of spatial analysis including measuring aspects of geometric features and identifying spatial patterns of geospatial objects that are represented as point, line, network, areal data, and 3-D surfaces.

- GIS and Spatial Modelling course that provides the students a foundation and understanding of various issues related to modelling and simulation in the GIS. It will address the concepts, tools, and techniques of GIS modelling (vector- and raster-based modelling). In addition, it will present modelling concepts and theory as well as provide opportunities for hands-on model design, construction, and application.

- NOAA training project and internship program course that includes: 1) a detailed review of many of the activities conducted by the branches in NOAA's Marine Chart Division and 2) a training project that demonstrates the student's ability to implement the knowledge gained during the certification.

This paper presents a newly established CAT B certificate program in Standards of Competence for Nautical Cartographers that is conducted at NOAA's main campus in Silver Spring, Maryland, USA. The CAT B certificate program provides NOAA a mechanism to both enhance building capacity within the organization and recognizing NOAA cartographers for their capabilities and efforts. In addition, such a program at NOAA can also be used to recruit new employees and help to build capacity in sister organizations. 